\title{
Encontros presenciais: uma ferramenta EAD?
}

\author{
Sheila da Costa Oliveira*
}

\begin{abstract}
Resumo: Neste texto, apresenta-se o conceito de Encontro Presencial (EP) como uma das ferramentas de um curso virtual, durante o qual se pode, utilizando a sincronicidade e a presencialidade concreta, preparar melhor os envolvidos no processo para usarem as ferramentas assíncronas, potencializando suas possibilidades interativas. Além disso, explicita-se um modelo básico de Encontro Presencial identificado, e utilizado em cursos de nível superior, discutindo-se as etapas e procedimentos que se revelaram mais prazerosas e eficazes na prática da interação alteritária, em dezoito encontros presenciais estudados ao longo de seis anos, em comparação com dois cursos virtuais de curta duração (média de três meses) que não apresentaram o encontro presencial como parte de sua rotina.
\end{abstract}

Palavras-chave: encontro presencial, educação a distância, alteridade, epifania.

\begin{abstract}
In this text, we presents the concept of Presence Meeting (PM) as a tool of a virtual course, in which we can, by using synchronicity and concrete presence, to prepare better the people involved in distance education to use the asynchronous tools and improve your interactive possibilities. Furthermore, we explicit one presence meeting basic model, used in high level virtual courses, and we discuss the steps and procedures that bring more pleasure and efficacy to students and teachers. We observed, during six years, eighteen presence meetings, and two virtual courses that no used presence meeting as standard procedure.
\end{abstract}

Key words: presence meeting, distance education, alterity, epiphany.

\section{Introdução}

Parece um contra-senso falar-se de encontro presencial (EP) no contexto da educação a distância, já que esta pressupõe conexão e interatividade, independentemente das noções tradicionais de espaço-tempo. No início da educação a distância formal, por volta de 1850 , os contatos entre alunos e professores eram realizados apenas por correio, telégrafo e arquivos impressos, assim permanecendo até mais ou menos 1930, quando ocorreram os primeiros encontros presenciais na Europa e nos Estados Unidos da América, (PETERS, 2004) principalmente para colocar as pessoas em contato e reforçar a noção de "educação e coletividade" e não apenas de "instrução individual", até então em voga, no contexto de EAD. Esse momento passou a existir até mesmo como forma de criar e manter uma identidade reconhecida para os grupos que se envolviam nessa modalidade educacional. Vendo-se uns aos outros, e localizados num espaço e num tempo precisos, ainda que rapidamente, os integrantes de cursos a distância aprenderam a reconhecer-se e a validar-se como participantes de um real processo educacional (NOBLE, 2004), provocando pouco a pouco esse efeito também na sociedade. No Brasil, os primeiros encontros presenciais foram realizados em São Paulo, ainda pelo Instituto Monitor, e ajudaram a vencer o preconceito com relação aos cursos a distância, dando rosto e voz aos educandos e educadores envolvidos no processo (BELLONI, 2002). Espelhavam, nessa época, a crescente complexidade desse modelo educacional, que já havia, em um curto intervalo de tempo, evoluído das correspondências individualizadas à formação de grupos ou turmas, à semelhança do ensino presencial. Mais tarde, com a criação dos radiocentros e telecentros, os alunos se reuniam para estudar juntos, tendo a figura do professor mediatizada. Com a implementação dos cursos a distância mediados por computador, esses momentos também passaram a ser usados no treinamento dos participantes quando aos uso das ferramentas eletrônicas. Atualmente, com a expansão contínua dos horizontes de EAD, novas reflexões sobre os encontros presenciais têm sido feitas. As observações e relatos presentes neste trabalho resultam de: a) estudo de dezoito encontros presenciais de nível superior, (duração média de 24 meses) em IES públicas e privadas, ao longo de seis anos como tutora e designer instrucional; b) estudo de dois cursos virtuais de curta duração em

\footnotetext{
* Doutora em Informática e Educação pela Universidade Federal do Rio Grande do sul, na área de linguagem comunicacional em EAD. Professora da Universidade Católica de Brasília.
} 
uma instituição pública e outra privada (média de 3 meses), sem encontros presenciais; e têm como objetivo oferecer subsídios ao planejamento/desenvolvimento de encontros presenciais, bem como à opção consciente de sua utilização ou não, dentro do processo pedagógico adotado pela instituição gestora do curso. Como orientadores das observações, utilizamos os conceitos de alteridade e epifania, tais como apresentados por Bakhtin $(1992 ; 1997)$ e Emanuel Lévinas $(1988 ; 1974)$, buscando identificar que procedimentos seriam capazes de suscitá-los em cursos virtuais. O uso desses conceitos justifica-se pelo fato de um encontro presencial colocar as pessoas face a face, frente a frente, interagindo com o Rosto do Outro e com toda sua carga afetiva e simbólica, a qual nos possibilita percepções e revelações que não ocorreriam sem esse encontro. Os EP observados foram registrados: quatro, em mídia audiovisual; seis, em mídia apenas auditiva; dez foram apenas relatados em formulário padrão, que continha espaços para a manifestação livre do observador. Os registros foram estudados e geraram um relatório, do qual as informações foram utilizadas para a produção deste texto.

\section{Um encontro presencial pode ser considerado uma ferramenta de EAD?}

A palavra ferramenta vem do latim ferramenta, (FERREIRA, 1986) e tem como sentido primeiro "utensílio de ferro de um trabalhador", ou, por extensão, "qualquer utensílio empregado nas artes e ofícios, conjunto de utensílios de uma arte ou ofício". Quando tomada em sentido figurado, pode ser entendida como "instrumento". Partindo desse conceito, a adequação dessa palavra a um encontro presencial pode ser percebida sob diferentes ângulos. Apesar de não constituir propriamente uma ferramenta, no sentido estrito do termo, o encontro presencial (EP) pode ser assim considerado no sentido metafórico, já que é um meio pelo qual os diferentes atores de um curso a distância podem estabelecer interações síncronas e presenciais. Contudo, o que ainda se vê abundantemente em EPs é a repetição de procedimentos do ensino convencional, pois essa modalidade de reunião pedagógica, parece-nos, ainda não encontrou a especificidade própria do meio educacional no qual se insere, principalmente porque a cultura de educação a distância no Brasil ainda está em formação. Torna-se necessário, então, caracterizar um encontro presencial considerando essa nuance, o que buscamos fazer a seguir.

\section{O que caracteriza um EP?}

a) Um encontro presencial é um espaço de interação alteritária e epifânica, e não uma aula convencional. Embora tenhamos a tendência de encará-lo dessa forma, o chamado "encontro presencial" não é uma aula, e não é nele que ocorre a maioria das atividades de um curso a distância. Portanto, não se planeja um EP como se planeja uma aula presencial, nem se deve esperar dele os mesmos efeitos. Há aspectos mais profundos a serem considerados, tais como a interação face a face entre os participantes do evento e, em especial, entre os colegas aprendentes (TARDIFF \& LESSARD, 2005). Nesse momento, a presencialidade concreta introduz novos elementos na aprendizagem realizada virtualmente, interferindo diretamente na qualidade das aprendizagens, e, embora a figura do professortutor tenda a tornar-se mais forte em determinados momentos, como no destinado a dirimir dúvidas de conteúdo que não foram sanadas via web, os discentes esperam que as interações entre eles sejam o foco principal, principalmente para reforçar neles mesmos o sentimento de pertença, enfraquecido de alguma forma pela modalidade virtual (BALBÉ, 2006):

É esquisito a gente vir fazer um encontro presencial e só ficar ouvindo, eu acho que a gente devia conversar mais, já que tá todo mundo junto. Aluno 198

Não é que eu não queira ouvir o professor, o coordenador, não é isso, eu até quero e muito, mas eu sinto falta de ter colegas mesmo, entende? Acho que aqui era a hora de fazer isso acontecer. Aluno 200 
Gostei muito do encontro, e acho que em termos pedagógicos, ou de conteúdo, tava 10! Mas faltou contato com as pessoas, sabe, eu ver quem era o fulano que estava no fórum concordando ou discordando de mim, perguntar pra ele alguma coisa... Sei lá, acho que no lado humano ainda pode melhorar muito, mas sem fazer a gente enrolar nem perder tempo, não é isso o que eu quero de jeito nenhum... Aluno 204

b) Um encontro presencial funciona como espaço de integração dos aspectos abordados/a abordar a distância: Muitas vezes, principalmente quando se trata de alunos com pouca experiência com a informática, a capacidade de aproveitamento individual a distância fica prejudicada. Desse modo, lacunas que continuariam abertas caso o estudo permanecesse individual ou limitado apenas à interação eletronicamente mediada, tendem a ser preenchidas no momento de interação presencial, do mesmo modo que percepções aparentemente completas de determinados aspectos do conteúdo podem ser redescobertas pela agregação de outros pontos de vista compartilhados durante um EP. A partir de um primeiro encontro presencial, quem ainda "tem o pé fincado" nessa noção interativa consegue ir substituindo-a aos poucos pela virtualidade e realizando a interação virtual com mais conforto.

c) Um EP revela aos envolvidos no processo muito da fidedignidade da instituição promotora do curso: Aspectos como organização, qualidade do material distribuído, o aspecto físico da instituição, agilidade e simpatia no atendimento influem na imagem que os participantes do curso formam dela e das rotinas pedagógicas e administrativas que propõe.

\section{Quanto deve durar um EP?}

A duração de um EP depende de sua freqüência ao longo do curso, bem como do grau de profundidade dos conteúdos a trabalhar e das necessidades específicas das turmas. Observamos os que duraram de três a quatro horas, e também os que duraram de dois a três dias, e cada métrica tinha sua finalidade e atendia determinados objetivos. Nos cursos nos quais não havia a previsão de EP, a maioria dos alunos solicitava pelo menos um, ou dois, no início e ao final, para abrir e fechar as atividades previstas com o encontro dos outros envolvidos no processo, apesar de não serem atendidos. Apenas os alunos que residiam muito distante da instituição promotora do curso não o solicitavam, por dificuldades de locomoção e hospedagem, mas propunham o uso de ferramentas como a áudio e a videoconferência para suprir a falta que sentiam dele.

\section{O que fazer nele e com ele?}

A definição das atividades de um EP, bem como do tempo necessário ao seu desenvolvimento, sofre a influência de vários fatores: (i) quantidade de encontros que haverá ao longo do curso; (ii) gradação das dificuldades encontradas no conteúdo do mesmo; (iii) proficiência tecnológica apresentada pelos participantes; (iv) ser ou não um encontro unidisciplinar.

No EP de uma disciplina virtual, o professor-tutor encontra-se sozinho com os alunos, e, nesse modelo, foi percebida uma forte tendência a se criar um espaço de realce de sua figura. Quando o encontro é multidisciplinar, congregando todas as disciplinas de um semestre totalmente virtual, ou de um bloco delas, a negociação a respeito do tempo a distribuir tende a tornar-se mais difícil. As atividades interdisciplinares evitam o alongamento da linearidade dos eventos previstos, mas cada tutor de disciplina tende a reclamar para si um tempo específico, temendo a perda de profundidade na abordagem do conteúdo. Como nem sempre isso é possível, a solução consensual mais contemporizadora é a de dar mais espaço a dois ou três tutores em cada encontro, para que todos se sintam contemplados pelo menos uma vez ao longo do semestre. Contudo, a necessidade de fazer encontros mais longos, de três dias, no caso dos cursos totalmente virtuais e de duração 
acima de 1 (um) ano, foi aventada várias vezes, mesmo já sabendo que isso significa um aumento de gastos para o aluno, quanto à hospedagem, e um aumento do tempo no uso de salas, equipamentos e funcionários, para as instituições promotoras. Além disso, como os tutores de disciplina também exercem funções em outras áreas da instituição promotora do EP, bem como em outras instituições, seria necessário planejar o encontro ainda com mais cuidado, para evitar choques de horários com aulas presenciais e outras tarefas específicas.

De acordo com essas diretrizes e também segundo sugestões/observações coletadas dos questionários de avaliação e rotinas de observações e vivência dos Encontros Presenciais estudados, uma boa sequiência para as atividades conteria: a) início com uma rotina de apresentação / integração dos participantes, com modificações do primeiro para o último encontro, já que se supõe um aprofundamento das interações pessoais ao longo do curso; b) exposição dialogada ou exercícios em grupo para dirimir dúvidas e integrar conteúdos trabalhados a distância; c) atividade grupal para aprofundamento de aspectos mais relevantes, com troca de informações e pontos de vista entre os grupos e exposição oral de resultados; d) prática de rotinas que não são passíveis de execução a distância; e) atividade de avaliação, seja individualmente ou em grupo, variando-se a modalidade de um encontro para o outro, para evitar a monotonia; f) encontro com especialistas da área ou com outras turmas remotas, para pequenas palestras, painéis de discussão, seminários e simpósios, de modo a apresentar outras visões do conteúdo que não a dos elaboradores do curso; g) atividade final de confraternização entre os participantes, para garantir a remotivação para o estudo e a melhoria das tarefas interativas realizadas a distância.

Tais etapas, se consideradas como variáveis importantes no processo de preparação de um encontro, guiam a seleção de estratégias de contato e condução do grupo, bem como a definição das modalidades de trabalho individual e coletivo mais adequadas aos momentos do encontro (apresentação das pessoas, discussão de dúvidas, trabalho individual ou grupal, avaliação, confraternização), aos indivíduos (mais ou menos proativos, mais ou menos lentos na realização de atividades previstas) e à turma (mais ou menos integrada, com maior ou menor grau de resposta proativa coletiva).

Todas essas variáveis somente são percebidas a contento por quem interage mais freqüentemente a distância com os participantes, no caso, monitores, tutores e pessoal de secretaria. Durante a pesquisa, observou-se que a proposição dos ajustes mais pertinentes partia de pessoas vinculadas a esses segmentos, sempre visando a um melhor atendimento dos alunos.

Tratemos agora, especificamente, de cada um dos momentos possíveis de um EP, indicando os que se mostraram mais bem recebidos nos encontros presenciais observados, e que propiciaram mais condições de contato alteritário e de percepções mais intuitivas e emocionais, em contrabalanço às rotinas lógico-racionais propostas nas páginas de conteúdo dos cursos:

\section{Recepção/apresentação/integração dos participantes:}

a) sorrindo e cumprimentando a cada um pelo nome, o que se torna possível com a confecção de crachás e a disponibilização antecipada destes, de modo que o participante já esteja devidamente identificado ao se aproximar da equipe de recepção. No primeiro encontro de uma das turmas, foi indicado pelos alunos como importante que alguém paciente e bastante simpático permanecesse no local de distribuição dos crachás, facilitando a localização deles, caso não tivessem sido entregues antes. Nos encontros de meio e final de curso, essa providência não foi apontada como necessária, muito embora a sua repetição provocasse o efeito de valorização pessoal, sempre positivo, além de facilitar a lembrança dos nomes, já que algumas pessoas não associam facilmente os nomes aos rostos.

b) fornecendo material de apoio às atividades do dia aos poucos, de modo a não desviar a atenção dos participantes para o material. Nas reuniões de avaliação de EP, foi constatado que seria mais recomendável selecionar o material necessário a cada uma das etapas do encontro e distribuí-lo à medida que fosse usado, com possibilidade de 
acondicionamento a uma pasta, para evitar perdas e manuseio de muitos itens ao mesmo tempo. A personalização de todo esse material (pasta, blocos, apostilas etc.) reforçou ainda mais a valorização pessoal dos participantes pela equipe gestora, causando ótima impressão na equipe discente. Associamos esse impacto positivo ao fato de o nome representar a interface simbólica do Rosto, resgatando, mais uma vez, a pessoalidade individual (LEVINAS, 1988).

c) familiarizando os participantes com o ambiente de realização do encontro, com a colocação de placas e setas bem visíveis e claras em suas indicações, para que todos possam deslocar-se com facilidade. Também surtiu efeito positivo a presença de responsável disponível para resolver dúvidas eventuais quanto à localização, devido à dificuldade natural de muitas pessoas em interpretar signos verbais e não verbais. Um dos coordenadores instituiu, no primeiro encontro, um "tour" com a turma, apresentando as instalações e relatando algumas das atividades importantes que nelas se desenvolviam, o que foi considerado muito positivo pela equipe discente.

d) colocando-se à disposição para registrar reclamações e sugestões, sem julgar de sua pertinência em presença de quem a apresentou, disponibilizando os meios para que os próprios participantes o façam: caixas / painéis / murais de sugestões com papel e lápis disponíveis, colocadas em locais estratégicos e não muito expostos à visão coletiva, para não inibir a participação daqueles que ainda acham que sugerir e criticar seja ofender;

e) início das atividades com a apresentação de cada um dos gestores do encontro, sempre num clima de cordialidade e simpatia, propondo a integração destes com os participantes, pela realização de dinâmicas de grupo adequadas ao momento e ao perfil das turmas.

II. Explicação da dinâmica do curso, da disciplina e/ou do semestre letivo, com apresentação nominal e breve pronunciamento de cada um dos envolvidos no processo de condução das atividades, (encarregado de suporte técnico, monitores, tutores, secretário escolar, coordenador e outros), simulando possíveis dúvidas dos participantes quanto a quem procurar para resolver essa ou aquela dificuldade ou pendência.

III. Apresentação da plataforma que hospeda o curso, bem como das ferramentas eletrônicas que serão utilizadas: download e impressão de documentos, cadastro on-line, atualização de dados a distância, envio de documentos, e-mail, chat, fórum etc, sempre visando ao conforto do aluno com relação à tecnologia disponível. Nesse momento, constatamos ser fundamental que a equipe de monitores, tutores e técnicos trabalhe em conjunto com a turma, para não deixar que a insegurança ou o desconforto com relação ao domínio de alguma rotina desmotivem ou bloqueiem os aprendentes. Foi considerada importante pelos alunos e tutores menos experientes a existência de um passo-a-passo que guie os usuários na execução dos procedimentos numa seqüência gradativa e cumulativa. Foi também constatada a necessidade de intervalos estratégicos, evitando que o número de informações num mesmo bloco de trabalho seja superior à capacidade de percepção/assimilação da turma e das pessoas em particular.

Foi constatado, durante a observação dos EP, que alguns procedimentos e atitudes da equipe encarregada de conduzir esse momento, apresentados como resposta a questionamentos e dúvidas, foram considerados pelos alunos como ofensivos ou depreciadores: revirar os olhos; respirar ruidosamente; alterar o tom de voz demonstrando irritação ou ironia; rir diante de dúvidas apresentadas pelos participantes; retirar o equipamento da mão do participante para executar em seu lugar a atividade; comparar o desempenho de um com o outro; comentários em voz baixa, entre os gestores desta etapa, fossem ou não referentes a pessoas ou atividades que estivessem sendo desenvolvidas, pois os participantes os encaravam como críticas veladas e depreciativas com relação a eles próprios, inibindo-se ou irritando-se. 
Todos esses procedimentos foram indicados como prejudiciais ao processo de interlocução síncrono e assíncrono, criando um desejo de afastamento para com a pessoa que os manifestou ou para com o segmento ao qual essa pessoa pertencia.

Os alunos que não tinham e-mail cadastrado freqüentemente solicitam tempo do EP para fazê-lo. Contudo, como essa rotina leva algum tempo, principalmente se os usuários não estivessem familiarizados com os procedimentos de cadastro e com os ícones da página de correio eletrônico, nem sempre esse tempo é concedido aos discentes. Acompanhamos as trocas de $e$-mails dos alunos que não puderam ser atendidos nesse pedido específico, e constatamos que levaram mais tempo para estabelecer contato efetivo com a equipe pedagógica (de duas a quatro semanas), ocasionando descompassos no acesso ao conteúdo e na execução das tarefas previstas. As primeiras mensagens desse grupo de alunos também se apresentavam tímidas, contendo declarações como as que transcrevemos a seguir:

\begin{abstract}
Desculpe pela demora, professora, mas só agora eu consegui entender como funciona esse negócio de e-mail. Minha filha fez comigo um monte de vezes até eu acertar, porque não queria ficar pedindo ajuda toda hora que precisasse. Tem um pouco de paciência comigo, tá? Perdi muita coisa? Tem como recuperar? Aluno 200

Professora, só agora estou respondendo suas mensagens, mas não foi por má vontade não. Meu sobrinho está me ajudando a fazer as coisas desse curso virtual, até eu me acostumar. E vou mandar mensagens pequenas, porque eu não digito, eu "cato". Mas não fala pra ninguém, não, viu? Aluno 198
\end{abstract}

Um dos grupos observados atendeu a essa solicitação, adotando também como prática que as primeiras trocas de mensagens entre os alunos, tutores, monitores, pessoal de suporte e secretaria fossem efetuadas nesse momento do EP. Para esse grupo, a demora na efetivação do contato pelos discentes caiu para 3, num total de 34 alunos matriculados, enquanto que, sem esse procedimento, o total de alunos com retardo no início das interações era de 14, num total de 29 matriculados. Após a implantação dessa rotina para os $e$-mails, e a observação do sucesso da iniciativa, foi decidido pela coordenação que o mesmo deveria ocorrer com relação ao fórum e ao chat, duas ferramentas de comunicação/colaboração essenciais ao sucesso de cursos virtuais. Desse modo, a partir do terceiro EP inicial desse curso, além de registrar o $e$-mail dos alunos, as seções do ambiente virtual destinadas a essas duas modalidades de interação passaram a ser regularmente visitadas, e a simulação de discussões síncronas e assíncronas foi realizada também enquanto estavam todos juntos no mesmo espaço, o que foi considerado positivo para a interação dos alunos entre si e da turma com os demais integrantes da equipe tecnológica, pedagógica e administrativa. Até o momento de encerramento da pesquisa, apenas mais um grupo de trabalho observado havia aderido a essa prática, com igual sucesso. Os outros dois preferiram não fazê-lo, pois realizavam um encontro presencial de apenas um dia, não havendo, segundo os responsáveis, tempo suficiente para a realização desse tipo de trabalho de ambientação. Acompanhamos também as trocas interativas desses dois grupos, e o número de alunos com retardo no início das interações, bem como com problemas na continuidade delas, nessas comunidades, continuou alto: em torno de $40 \%$. Os alunos incluídos nessa porcentagem também foram os que apresentaram maiores problemas com datas de entrega de trabalhos, baixa participação nos fóruns de discussão e ausência nos chats, o que nos levou a verificar uma relação de causa e consequiência entre a ausência de ambientação tecnológica presencial e o desempenho do aluno durante o semestre letivo.

IV. Tratamento de conteúdo específico: Encerradas as atividades referentes ao contato inicial e à interação dele decorrente, foi comum, nos EP observados, o tutor (encontro de disciplina) ou a equipe (encontro de curso/semestre virtual) continuarem as atividades apresentando o conteúdo específico que seria trabalhado ao longo do encontro, desfazendo mitos e impressões negativas a respeito de componentes curriculares e apresentando os conceitos básicos que o aluno precisaria dominar como pré-requisito à execução das 
atividades propostas. O entusiasmo e a clareza na exposição, bem como a estética do material apresentado, mostraram-se essenciais para conseguir-se a atenção e a motivação dos alunos. Apresentar as páginas das aulas, exemplificar as rotinas dos exercícios, acolher dúvidas e perguntas com gentileza e precisão na resposta sempre provocaram reações positivas por parte dos alunos. Observamos mesmo mudanças na corporalidade, com os alunos se mostrando mais relaxados, sorridentes, abertos a conversas e a perguntas, à medida que se sentiam mais donos do ambiente virtual, efetuando a navegação com segurança. Visitar os links indicados e acessar as leituras complementares também se mostraram ações prazerosas, provocando, conforme a fala de vários alunos, "uma vontade de percorrer tudo e aproveitar".

A partir do segundo encontro, quando já se pressupunha um aprofundamento das relações interpessoais inicialmente estabelecidas e uma melhoria na proficiência tecnológica, não houve mais necessidade de se investir tempo nesse aspecto.

V. Dúvidas no ar: Percebemos, ao longo dos EP observados, que era preciso reservar tempo para dirimir dúvidas relativas ao conteúdo, para evitar o acúmulo de lacunas que impedissem o bom desenvolvimento do conteúdo na próxima etapa a distância. Como algumas dessas dúvidas eram coletivas, foi implantado um momento de assembléia para dirimi-las. Também foi constado que, em caso de dúvida individual, o aluno se sentiria melhor sendo consultado sobre sua preferência em tê-la respondida em grupo ou individualmente. Um dos grupos observados coletava sistematicamente essas perguntas para atualizar o FAQ do curso, o que contribuía para a solução de problemas sem necessidade de esperar o próximo encontro presencial. Os outros três grupos, mesmo informados do sucesso dessa iniciativa, alegaram não poder implantá-la por falta de pessoal disponível para a seleção do material, sua organização e publicação no ambiente virtual, já que a equipe conseguia apenas alimentar as páginas de conteúdo e manter em funcionamento as seções interativas das plataformas.

VI. Trabalhos em grupo: Observamos que a organização dos grupos de trabalho, no primeiro momento presencial do curso/semestre, era importante para que as interações e preparações das atividades propostas em equipe não se iniciassem no meio virtual com pessoas desconhecidas. O suporte técnico e a tutoria precisavam trabalhar juntos para providenciar a organização dos grupos, de preferência colocando as fotos e os nomes de todos em cada ícone de abertura das equipes. Os monitores e tutores propunham pequenas tarefas aos grupos assim formados, para que procurassem executá-las sem conversarem presencialmente, cada um na sua máquina, já exercitando o chat como ferramenta síncrona de comunicação e o up-load/download de arquivos como troca de informações. Durante um dos EP observados, verificamos que seria interessante indicar um coordenador de grupo, o qual se encarregasse de fazer a verificação final do documento e enviá-lo. Caso contrário, chegavam ao monitor e ao tutor diversas versões do mesmo documento. Também foi visto ser bom fazer rodízio dessa função entre os alunos, de modo que todos experimentassem a responsabilidade da tarefa e não se sentissem menos importantes que os outros participantes da equipe.

Porém, se o trabalho em grupo presencial já é uma prática complexa, a distância observamos que essa atividade pode atingir graus de dificuldade com os quais os indivíduos não consigam lidar muito bem sem apoio suplementar. A conversa por e-mail, chat ou fórum, com os colegas, para produzir um resultado coletivo sem encontros presenciais obtém com frequiência resultados pobres, na maioria das vezes concentrados em um ou dois membros da equipe que tenham mais desenvoltura nesse contexto. Para melhorar esses resultados, dois dos grupos de trabalho observados optaram por realizar as atividades em grupo nas seguintes modalidades: a) totalmente durante os EP, por entender que assim o trabalho realmente seria feito pelos alunos e em grupo, além do que, a orientação dos tutores das disciplinas ficaria mais fácil, já que todos se encontravam no mesmo espaçotempo; b) iniciando no EP, com divisão de tarefas e execução dessas a distância e troca de 
materiais entre os participantes por e-mail, chats $e$ fóruns ; c) iniciando no modo virtual e finalizando no EP.

Observamos que os dois primeiros modos propiciaram menos problemas durante as interlocuções, o que nos levou a correlacionar a importância da presencialidade na coordenação de ações, principalmente se essas ações ainda precisam ser definidas coletivamente e têm desdobramentos posteriores.

A experiência foi repassada aos demais coordenadores, mas, apesar de acharem a idéia interessante, não optaram por adotá-la, já que privilegiavam as atividades individuais. Quando indagados a respeito das razões dessa preferência, tutores e coordenadores declararam não confiar em trabalhos em grupo, "nem mesmo nos cursos presenciais, que dirá a distância". Essa resistência demonstrou a predominância da instância de controle, ainda muito presente no contexto educacional da EAD.

Foi também constatado que, quando os grupos tinham tempo de apresentar presencialmente os resultados do que havia sido produzido a distância para a turma, a valorização do esforço individual e coletivo e a troca de experiências e conceitos sempre enriqueceram o conteúdo padrão, acrescentando-lhe saberes novos, e tornando as aprendizagens mais significativas. Essas apresentações também puderam ser usadas como um dos instrumentos de avaliação, inclusive com peso maior nas competências de expressão oral, que, também constatamos, precisam ser incentivadas e desenvolvidas ao longo de todo o curso, juntamente com as de escrita, que predominam nas interações a distância. No entanto, a qualidade dos trabalhos não caiu, quando um dos grupos observados usou a apresentação oral como rotina pedagógica não avaliativa, o que nos sugeriu uma conexão fraca entre qualidade e controle avaliativo. No entanto, como nenhum outro grupo se dispôs a fazer a mesma experiência, não houve elementos suficientes para uma conclusão a respeito.

Durante a apresentação dos grupos, notamos que seria preciso incentivar a atenção e o respeito pelo produto de cada equipe, principalmente quando a turma fosse composta por alunos mais novos, os quais se mostraram mais propensos à dispersão e à perda de informações durante as rotinas orais. Essa característica, identificada em uma das reuniões de avaliação de EP, levou a equipe pedagógica à necessidade de ajustes. Foi então reservado um tempo específico para comentários da turma, do monitor e do tutor, de acordo com critérios e dinâmicas previamente estabelecidos. Também foi criado um formulário para sistematizar anotações a partir da apresentação oral dos grupos, usando-se esse material em momentos de síntese ou na preparação de novos trabalhos em grupo ou individuais. Dessa forma, a construção do conhecimento proposta por um grupo passou a agregar também a contribuição dos demais, valorizando sua participação em presença uns dos outros e sua interferência direta no progresso dos estudos coletivos. (AXT \& MARASCHIN, 1997)

VII. Avaliação: Segundo o ABRAEAD 2005, 92\% das instituições que trabalham com cursos a distância utilizam o Encontro Presencial como espaço de trabalho avaliativo, estando essa modalidade de atividade prevista em todos os encontros observados durante a pesquisa. Segundo o que observamos, isso se deve, fundamentalmente, a dois fatores:

a) Associa-se ainda, e muito, a avaliação ao controle do grupo de aprendentes, controle esse que precisa, para ser eficaz, exercer-se na presencialidade. Inclusive, muitas das falas dos tutores recém-chegados ao ambiente virtual, referem-se a como confiar em trabalhos que não são feitos sob a sua vigilância. Declarações desse teor indicam uma inquietude significativa com relação a fatores não conteudísticos, não intelectivos, mas fundamentalmente emocionais, tendo como fulcro o sentimento de confiança, indispensável a bons relacionamentos e interações, em qualquer instância. (THURLON, 2004);

b) As equipes pedagógicas ainda precisam confirmar em presença os indicadores observados a distância, para ver, como bem disseram explicitamente oito dos tutores 
pesquisados, se o "aluno se sustenta" na interação face a face. Novamente, essa necessidade de confirmação nos remete à problemática da confiança, que, embora minimizada nas discussões institucionais, é ainda um dos motores subjacentes às ações pedagógicas que caracterizam um curso a distância.

Quando iniciamos a observação dos EP estudados, cada disciplina dos cursos propunha uma avaliação isolada, trabalhando como disciplinas virtuais num semestre presencial, e não como integrantes de um bloco de disciplinas on-line (ROSA, 2006). Durante as entrevistas com os tutores e coordenadores, identificamos que esse era o modo para o qual tinham sido preparados como docentes do ensino superior. Muitos declararam estar tentando vencer essas limitações, enquanto outros não viam motivos para fazê-lo, pois estavam "dando conta do recado". Esse modelo linear, além de tornar o encontro presencial estafante para os alunos, que precisavam responder a vários instrumentos avaliativos, reforçava o isolacionismo da equipe de tutores, a especialização e a fragmentação dos conteúdos - já que cada um deveria preparar sozinho o seu material avaliativo. Durante as reuniões de avaliação dos EP, aos poucos foi-se implantando o modelo de avaliação multi e interdisciplinar ${ }^{1}$, reduzindo a quantidade linear das tarefas e possibilitando a percepção de conexões antes encobertas. A partir dessa implantação, o trabalho coletivo da equipe de tutoria também foi potencializado, pois era preciso reunir-se em pequenos grupos, de dois ou três, para prepararem os instrumentos avaliativos (MONAT, s.d.)

Todos os EP observados previam também uma avaliação do encontro, aplicada ao final de todas as atividades, em formulário específico, não muito longo, mas com espaço para questões fechadas (de fácil tabulação) e abertas (que permitiam maior expressão individual). Os dados obtidos por meio desse instrumento eram cuidadosamente tabulados pela equipe pedagógica e examinados com critério.

Os resultados, no entanto, ficavam restritos às equipes de coordenação e tutoria, o que não provocava todos os ajustes necessários para o próximo EP. Um dos grupos pesquisados resolveu, então, disponibilizar os resultados na página do curso, para todos os segmentos da equipe, de forma transparente, inclusive com a listagem das sugestões de providências com vistas aos ajustes necessários. Observamos que essa avaliação sistêmica e aberta, sincera e seriamente conduzida, tornou-se um dos mais eficazes meios de promover a integração dos participantes com a equipe gestora, fazendo com que o "curso deles" se tornasse "o nosso curso" e melhorasse significativamente os níveis de participação e envolvimento. Houve, inclusive, sugestão de soluções possíveis de um segmento para outro, que, quando adotadas, revelaram-se eficazes, surpreendendo mesmo os integrantes do segmento receptor da sugestão, que não haviam percebido uma ação possível devido ao alto nível de imersão/implicação no contexto. O olhar do Outro, no entanto, fora capaz de realizá-lo. (BAKHTIN, 1997; LÉVINAS, 1988)

Mais uma vez, os outros três grupos não acompanharam a esse na implantação da mesma rotina, alegando que a divulgação de tudo exporia as fragilidades internas, o que não seria bom para a instituição. Continuaram, pois, mantendo as informações sob a gerência da coordenação, e cada setor só era informado do que lhe dizia respeito diretamente. Nesses grupos, portanto, não houve a possibilidade de interação e alteritária

\footnotetext{
1 Interdisciplinaridade significa, entre outras acepções possíveis, uma relação de reciprocidade, de mutualidade, frente ao problema do conhecimento, substituindo uma concepção fragmentária por uma concepção unitária do ser e do saber humanos. Essa noção pressupõe abertura, ausência de preconceito, valorização do saber coletivo, opinião crítica. Multidisciplinaridade contempla o conjunto de disciplinas que serão trabalhadas simultaneamente, mas sem obrigatoriamente exibir as relações entre elas, e sem cooperação entre as áreas do saber. Recorre-se a informações de várias matérias para estudar um determinado elemento, mas sem a preocupação de interligar as disciplinas entre si. Já a transdisciplinaridade é o princípio teórico que busca intercomunicação entre as disciplinas, tratando de um tema comum (transversal), e eliminando as fronteiras entre as disciplinas. (AGÊNCIA EDUCA BRASIL, 2001-2004)
} 
nesse aspecto, permanecendo a evolução do modelo de EP em modo lento e sem muitas surpresas.

VIII. Encerramento: para encerrar o encontro, os diferentes grupos observados utilizavam as seguintes estratégias: a) revisão da agenda prevista para o próximo intervalo a distância: tarefas a entregar, chats programados, apresentação da temática dos fóruns e outros, de modo a ajudar os alunos a manterem a regularidade dos estudos e contatos. Essas modalidades foram mais observadas nos grupos que atuavam de acordo com paradigmas educacionais mais tradicionais, embora também estivessem presentes no grupo considerado como "progressista" e "arrojado"(LITWIN, 2000); b) atividades de descontração/integração, tais como dinâmicas de grupo, comemoração dos aniversários, fotografias coletivas que depois se publicavam no ambiente virtual, estratégias utilizadas pelo grupo com atitudes pedagógicas mais progressistas, sempre na busca de manter as pessoas motivadas, não somente para terminar um curso, mas para se desenvolverem juntas, tanto nesta quanto em outras oportunidades.

Ambos os procedimentos revelaram-se positivos, envolvendo mais a turma quando apareciam combinados, e não excludentes. As atividades de caráter mais afetivo repercutiam positivamente na regularidade das interações assíncronas, bem como na consistência das postagens de fórum e na execução de trabalhos em grupo. Após um EP em que essas atividades não ocorriam, (e foram oito, os observados com essa particularidade) esses indicadores perdiam em quantidade e qualidade, o que nos sugeriu uma conexão forte entre a interlocução afetiva e atividade pedagógica.

\section{Conclusão}

Vimos que encontros presenciais não precisam necessariamente constar da proposta pedagógica dos cursos, mas, quando ocorrem, influem positivamente na qualidade das aprendizagens que se realizam, pois estreitam as relações entre as pessoas e entre essas e as instituições. Esse modelo básico de EP pode ser reconfigurado, de preferência consultandose os planos anteriores para evitar repetição de rotinas e conseqüentemente desmotivação dos alunos. O uso de uma grade de planejamento padrão mostrou-se eficiente para assegurar isso, podendo ser modificada de acordo com a conveniência de cada grupo de trabalho. Observamos também que, quando representantes de todos os segmentos envolvidos participavam do planejamento do encontro, de preferência presencialmente, o desenvolvimento das atividades durante o EP acontecia mais tranqüilamente, o que atribuímos ao fato de a visão geral do produto estar assegurada a todos, graças ao processo de interlocução globalizante. A autoria e a construção de sentidos, dessa forma, integravam o planejamento, fazendo com que ele se tornasse, ao mesmo tempo, um produto da equipe e um objetivo para a equipe como um todo. (AXT \& MARASCHIN, 1997) Observamos também que um encontro presencial pode ter um modelo básico elaborado por gestores, mas sua finalização depende essencialmente da interferência do professor-tutor, para que se façam as adequações necessárias às características das turmas com as quais trabalha. Além disso, quando os próprios aprendentes são chamados a participar de sua organização de alguma forma, o sentimento coletivo de autoria demonstrou influenciar a qualidade das interações, que se tornaram mais plenas e gratificantes, afetando também a melhoria da qualidade das aprendizagens efetuadas. Portanto, embora convencionalmente não se dê ao encontro presencial o mesmo status das ferramentas de interação eletronicamente mediadas, pudemos constatar que sua utilização adequada eleva-o ao patamar de catalisador, contribuindo para a coordenação de ações e potencialização das interações entre os segmentos que compõem cursos virtuais, bem como entre as pessoas, fazendo com que se redescubram como sujeitos umas para as outras, reforçando sua própria identidade pela aceitação/convivência com as diferenças. 


\section{Referências Bibliográficas}

AXT, Margarete. \& Cleci Maraschin. Prática pedagógica pensada na indissociabilidade cohecimentosubjetividade. In: Revista Educação \& Realidade, 22(1):57-80. Porto Alegre: jan/jun, 1997.

BALBÉ, Marta Maria Gonçalves. A interlocução entre professor tutor e aluno na educação a distância. In: http://www.inep.gov.br/pesquisa/bbe-online/det.asp?cod=58771\&type= Acesso em 15/07/2006 BAHKTIN, Mikhail. A Estética da Criação Verbal. Trad. PEREIRA. Maria Ermantina Galvão G. São Paulo: Martins Fontes, 1997.

---------. (Volochinov). Marxismo e filosofia da linguagem.. 6 ed. São. Paulo: Hucitec, 1992.

BELLONI, Maria Luiza. Ensaio sobre a Educação a distância no Brasil. In: http://www.scielo.br/scielo.php?script=sci_arttext\&pid=S10173302002000200008\&ptntm=iso Acesso em 07/10/2002.

FERREIRA, Aurélio Buarque de Holanda. Novo Dicionário Aurélio. 22. ed. Rio de Janeiro: Nova Fronteira. 1986.

LEVINAS, E. Totalidade e infinito. Trad. José Pinto Ribeiro. Lisboa: Edições 70, 1988, p.26, 38.

- Autrement qu'être. Paris: Du Seuil, 1974.

LITWIN, Edith (org). Educação a distância: temas para o debate de uma nova agenda educativa. Porto Alegre: Artmed, 2000.

MONAT, André et allii. Estratégias para a individualização e tratamento adequado dos erros cometidos

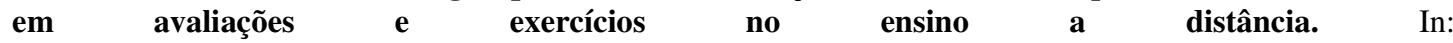
http://www2.abed.org.br/visualizaDocumento.asp?Documento_ID=45

NOBLE, David F. Le lourd passé de l'enseignement à distance. In: http://www.mondediplomatique.fr/2000/04/NOBLE/13691 2004. Acesso em 22/05/2006

PETERS, Otto. A educação a distância em transição: tendências e desafios. Trad. Leila Ferreira de Souza Mendes. São Leopoldo, RS: Ed. Unisinos, 2004.

ROSA, Iara Sanches. Soluções para EAD on-line numa perspectiva construtivista. Tese de doutorado. In: http://teses.eps.ufsc.br/defesa/pdf/12910.pdf Acesso em 21/10/2006

TARDIF, Maurice \& LESSARD, Claude. O trabalho docente: elementos para uma teoria da docência como profissão de interações humanas. [Trad. João Batista Kreuch] 2. ed. Petrópolis: Vozes, 2005.

THURLON \& LENGEL \& TOMIC. Computer Mediated Communication: social interaction and the internet. London: Sage, 2004. 